\title{
Epistemology of Science, Science Literacy, and the Demarcation Criterion: The Nature of Science (NOS) and Informing Science (IS) in Context
}

\author{
Teresa Castelão-Lawless \\ Grand Valley State University
}

castelat@gvsu.edu

\begin{abstract}
The result of misunderstanding science by students is their inability as future citizens to impact science public policies. The solution argued last year included creating courses in science studies serving two purposes: destroy students' stereotypical certainties about science and help them become "historical realists" in regard to scientific practices. But we also speculated that dismissing the myth of scientific objectivity and teaching the historical and sociological underpinnings of science might lead to turning students into epistemological relativists. We now have a solution to the social-constructivist trap stemming from studies of science. This paper inquires into American contexts such as scientific illiteracy, postmodernism in high schools and colleges, and the media, all of which help produce a generalized inability to demarcate science from pseudoscience. Science studies courses guide students into both making epistemological distinctions and understanding the nature of science. Informing methodologies, course format, and bibliography follow.
\end{abstract}

Key words: demarcation science/pseudoscience; epistemology of science; nature of scientific practice; scientific illiteracy; pedagogical methods

\section{Introduction}

This paper is a continuation of "Informing Science (IS) and Science and Technology Studies (STS): The University as Decision Center (DC) for Interdisciplinary Research." There, we argued that students at Grand Valley State University could be divided into two groups, each with different conceptions of science and its relations to technology. One is the group of the naïve robust realists, mostly made up of science majors, who assume unquestioningly that scientific methodologies and objectivity clearly describe scientific processes. The group of naïve relativists are humanities students who accept uncritically that science suffers from the same type of epistemological arbitrariness to which other human activities are prone. We had also speculated that destroying the myth of scientific objectivity (at least as it has been traditionally defined), and teaching the historical and sociological underpinnings of science might lead to the

Material published as part of these proceedings, either on-line or in print, is copyrighted by Informing Science. Permission to make digital or paper copy of part or all of these works for personal or classroom use is granted without fee provided that the copies are not made or distributed for profit or commercial advantage AND that copies 1) bear this notice in full and 2) give the full citation on the first page. It is permissible to abstract these works so long as credit is given. To copy in all other cases or to republish or to post on a server or to redistribute to lists requires specific permission from the publisher at publister@intormingscience.org undesirable effect of having all students, whether they started out as naïve realists or as naive relativists, fall into the constructivist/relativist trap. The purpose of this paper is to explain how the social constructivist effect that stems from perceiving science symmetrically with other types of knowledge as well as from the relativistic intellectual legacy of post-modernism can be avoided. We need to do this 
while enabling students to recognize crucial epistemological distinctions between science and pseudoscience.

\section{Problem}

Contrary to the expectations of French positivist A. Comte (1855), there is no evidence of a direct causal connection between the growth of scientific knowledge and a rejection of non-scientific ways of thinking. The size of the scientific community and the applications of science to social uses are unprecedented. Yet, magic, astrology, and other non-scientific belief systems are as rampant today as they were in the seventeenth century. On the other hand, even those who are familiar with some important scientific principles, and who were therefore given some scientific education, are still basically illiterate in relation to the real nature of the scientific inquiry and the applications of science to everyday life.

We underscore the following epistemological categories that may help explain erroneous perceptions of science by the public: scientific illiteracy, post-modernism in high schools and colleges, the popularization of bad science by the media, and the assimilation of pseudoscience into previously orthodox scientific fields. These categories ought to become background knowledge for professors of science studies. They should also inform the context and content of informing methodologies such as course design, discussion of case studies, research projects, and bibliography of readings. Science studies courses must provide students with analytic tools for studying the complex nature of science, for understanding the dynamic tensions found in current scientific practices, and for acknowledging its historical rationality. These have to be complemented with critical thinking methodologies that enable students to test the validity of knowledge claims made in the name of science as well as the rationality of justified true beliefs.

The demarcation criterion between science and pseudoscience is a fundamental tool to future citizens regardless of whether they are to become directly involved in the scientific process itself or merely as participants and voters in public science policymaking. Donald Kennedy pointed out recently that there are two reasons for why we should "look at undergraduate education in the sciences (...) [S] ociety needs to prepare an adequate number of talented young people to do science and to do it well. At the same time, public policies increasingly hinge on scientific and technical issues. How well those decisions are made depend on whether policy-makers and voters have gained, in their higher education, an adequate literacy in science." (D.Kennedy, 2001a, 1557)

\section{Scientific IIliteracy}

Update 2001-2002, published by the American Association for the Advancement of Science (AAAS Project 2061, intended to reform K-12 education in natural science, social science, mathematics, and technology) defines a "science literate person" as someone that: is familiar with the natural world; understands some of the key concepts and principles of science; has a capacity for scientific ways of thinking; is aware of the important ways in which mathematics, technology, and science depend upon one another; knows that science, mathematics, and technology are human enterprises and what that implies about their strengths and weaknesses; is able to use scientific knowledge and ways of thinking for personal and social purposes. $(A A A S, 3)$

If we are to take this definition seriously, it follows that there are very few scientifically literate people in the United States. But, contrary to what the report suggests later on, we believe that strengthening science and mathematics skills does not per se indicate an automatic ability to understand "scientific ways of thinking" or to consciously use it "for personal and social purposes," let alone an acquired ability to discriminate science from non-science. It is not rare to find that college students who solve scientific problems still cannot explain the "underlying concepts behind them."(Stokstad, 2001a, 1610). But, on the other hand, science courses alone cannot be accountable for imparting to students a basic knowledge of 
broader social and political forces that direct scientific research or helping them acquire intellectual and critical skills that enable them to distinguish good science from pseudoscience, and scientific failure from scientific misconduct.

Students and the public at large are unaware of the stark dissonance between acceptance of conclusions reached by scientific experimentation and belief in radical scientific ideologies. In fact, "most of our science students retain an unscientific outlook even tough thy succeed in mastering some scientific ideas and techniques." (Bunge 1989a, 272) It is not unusual, for instance, to have biology majors witness evolutionat-work in the laboratory and its corroboration by other fields like geology but then reject uncritically the relevance of evolutionary theory as an explanatory model for human behavior. This reaction is similar to that of the community of many professional biologists when E.O. Wilson first suggested that possibility in his Sociobiology (1975). That both non-experts and experts in biology reach the same conclusion should make us cautious of simply correlating a narrow definition of scientific literacy with a deep understanding of the incompatibility between science and pseudoscientific ways of thinking.

Belief in the paranormal in North America increases with education: "Acceptance runs at 26\% among people with primary education, 55\% among high-school graduates, and 64\% among university graduates." (Bunge, 1989a, 272-273). A survey on public knowledge of science in the United States showed that in 1988 " $50 \%$ of American adults [rejected] evolution, and $88 \%$ [believed] astrology is a science." (Bunge 1989a, 270) Also, 50\% of American teenagers believe in "ESP and 29\% in witchcraft." (Bunge 1998a, 273) A Harris Poll revealed "that $94 \%$ of adults believe in God, $89 \%$ believe in heaven, $73 \%$ believe in the Devil, and 73\% believe in hell." (Sirico, 2001a, A10) A 1996 Gallup Poll indicates that 35\% of Americans believe in telepathy, $17 \%$ have consulted a fortune-teller or psychic, $33 \%$ believe that houses can be haunted, and $18 \%$ believe that they have been in touch with someone who has died. (Schick and Vaughn, 1999, 6) Yet another study indicates that "students in American schools consistently rank at the bottom of all those from advanced nations in tests of scientific knowledge, and furthermore roughly 95\% of the American public is consistently found to be scientifically illiterate by any rational standards.'(Goodstein in Lewitt 1999, 161) Although these surveys were all conducted at different times, for different purposes, and in different areas of the Continent, they seem to point toward a special correlation between scientific illiteracy and belief in pseudoscience. This picture prevails regardless of the population's level of education.

We must therefore distinguish three types of scientific literacy: 1. "cultural scientific literacy ("a grasp of certain background information" about science; 2. "functional scientific literacy" ("to be able to converse, and write coherently, using scientific terms (...) in (...) a meaningful context") and 3. "true scientific literacy" (one is "aware of the major conceptual schemes that form the foundations of science, how they are arrived at, why they are widely accepted, how science achieves order (...) and the role of experiment in science). Only the latter type of scientific literacy allows the individual to "extrapolate their skills to societal issues." (Shamos 1995, 88-90) We argue that access to this third level of scientific literacy can be achieved in science studies courses if we teach students about the nature of science and the demarcation criterion between science and pseudoscience. But the task is immense, as the world both inside and outside of academia pulls them in the opposite direction of treating these belief systems symmetrically.

\section{Post-Modernism in Science Education}

A consequence of the inability to understand the nature of science and science's epistemological implications include holding mutually exclusive beliefs about the world, as well as a generalized confusion regarding what is science and what is ideology, what is real science and what is voodoo science, (Park 2000) what is justified true belief and what is what we would like to believe. One cause of the inability to demarcate science from non-science has been the infusion of social constructivism into the multicultural science education agenda in high schools. Ethnomathematics and critical mathematics are cases in point. 
In an effort to celebrate diversity and enhance self-esteem, (Atwater 1996a, 822) students in these mathematics classes are led to believe that they can construct mathematics according to their subjective feelings and cultural backgrounds. The same goes for science classes. Encouraged to "negotiate scientific meaning," (Atwater 1996a, 826) students assume that scientific knowledge is not the result of consensus over epistemic rigor but a mere product of rhetorical skills applied to symmetrically valid worldviews. The result is a kind of "epistemological relativism," (Harding 1992a, 576) where science depends on who appropriates the term for their own cognitive territory. In other words, if you believe that you are doing science, then that is what you are doing. Those who claim that scientific orthodoxy has standards of rigor in relation to which other ways of knowing must conform to and be tested against in order to be identified as science are accused by the epistemological relativists of being "ethnocentric."

Levitt lists five thematic conceptions that "pervade the discourse of current attempts to "reform" science teaching": Knowledge of science is "constructed" by the student rather than "learned"; Science, like all knowledge, is "socially constructed"; All "knowledge" is discursive practice, the verbal and linguistic result of interaction of "available texts"; Every culture has its own distinctive mode of apprehending the world, its own "way of knowing"; All individuals are comparably gifted in their innate ability to acquire knowledge. (Levitt 1999, 172)

Eagerness for political correctness in regard to cultural world views makes relativists accuse the scientific community of being overly critical and dismissive of alternative ways of knowing. A very serious consequence of an "anything goes" principle of all-inclusiveness it that it makes one unable to distinguish real science from false science, of which Lysenkoism and eugenics are tragic examples.

\section{Mass Media}

The mass media are also to blame for the disconcerting inability of the population to distinguish cutting edge science from normal scientific work and real science from sensationalism. As Levitt argues, "the culture, as well as the frankly commercial purpose, of newspaper publishing creates a filter that selects stories - and emphasizes elements within stories - that do not accord with scientific judgment or the reality of scientific work." (Levitt, 1999, 231) First, it only publicizes scientific breakthroughs while hiding that science is normal research punctuated by rare episodes of extraordinary research. (Kuhn, 1970) Second, it conveys that cutting edge science, usually performed by "scientists" working outside of the mainstream, is always happening and stems from the work of highly creative but outcast geniuses, and it involves destroying traditional scientific assumptions. Third, it leads people to believe that all novelty that is antagonized by the scientific status quo means that conventional scientists impede scientific advancements that they perceive as affecting their own special interests. Fourth, it points to pseudosciences as cases of real science that are consistently dismissed by the scientific community on ideological grounds. The subliminal message in these instances of misrepresentation of science is that scientific knowledge ought to lie in the eye of the beholder and that all ideas can be scientific as long as some group of people identifies them as such. These images of science by the media can only reinforce scientific relativism, social constructivism, and conspiracy theories. Again, even those who had courses in science are not immune from the wrong perceptions of science conveyed by the media and become, therefore, scientific illiterate in respect to the demarcation criterion between science and pseudoscience.

\section{Alternative "Scientific" Worldviews}

Another cause (and consequence) of scientific illiteracy is the introduction of pseudoscience into scientific fields. Medical institutions in the United States condone use of acupuncture, homeopathy, meditation, chiropractic, and qigong on the basis of spurious factual evidence of their success in treating disease and at great financial cost to believers. The financial benefits of turning a blind eye to realistic standards of medical treatment is immense. It is not surprising that hospitals are inclined to relax their controls regard- 
ing alternative therapies, especially in view of the economic impact those therapies have in the larger community. A report shows that "the estimated number of visits to unconventional medical providers (425 million annum) exceeded those to all United States primary care physicians (388 million). The estimated cost, $\$ 10.3$ billion/annum out of pocket compares to $\$ 12.8$ billion spent out of pocket annually for all hospitalizations in the United States." (Weissmann in Gross, Levitt and Lewis 1996,183)

Qigong therapies are accepted without critical assessment by the public of claims that its masters make in regard to its methodologies as well as its success in curing diseases such as cancer and Aids. One master said that "Qigong is an ancient Chinese interdisciplinary science that integrates medicine, martial arts, culture, and other sciences" (p.2); "You are drinking the quantum soup when you inhale, which forms the river of your life force in your body with intelligence, maturity and fluidity; (...) be aware and get in touch with the quantum level of your self during Qigong practice and daily life" (p. 16); "Qigong aims to synchronize with the environment energy dynamics to reach internal and external balance (holistic health)" (p.17). In the case of the curative success of the practice, the same master says: "If you have cancer and are dying, or have a recurrence, I want you to know that in Qigong "there is an opportunity". For cancer, according to the Chinese Wisdom School's study, from 1991 to 1994, practicing PQQD wisdom Qigong cured four percent of cancer patients. However, the majority of cancer Qicong practitioners enjoyed a better quality of life, such as having less pain, living longer than their physicians expected, eating and sleeping better, and dying peacefully without struggling and suffering." (p. 22)(Chung 2000)

Statements such as the above, which interject scientific language in the middle of magical thinking, have a tremendous appeal to cancer patients, who are led to believe that a study on cancer cure rates conducted by none other than a Qigong school legitimize the reliability of Qigong techniques. Contrary to their rhetorical appeal, these claims are totally unscientific. One of the responsibilities of science studies professors is precisely that of convincing students that knowledge of the critical and self-correcting mechanisms of science, as well as critical thinking tools to demarcate science from pseudoscience are crucial to avoid the social, psychological, and financial traps set up by non-scientific ways of knowing.

\section{Demarcation Criterion and Nature Of Science (NOS)}

The demarcation criterion of science was one of the tenets of the positivists of the Vienna Circle, a group formed by scientists and philosophers in 1927. One project of was to get science rid of metaphysical claims, to study the formal or logical structure of scientific statements, and to reason through the epistemological consequences of developments in theoretical physics such as relativity and quantum mechanics. They were also interested in the problem of verification and took facts to be neutral in relation to theories.

The problem of demarcation was developed especially well by former positivist Karl Popper, who substituted the verification principle by "falsification." It was his belief that a characteristic of scientific theories is their openness to rejection on grounds of their being disconfirmed by future experimental testing. Those theories that cannot be falsified, or in relation to which one cannot find counter-instances, are pseudosciences. It must be possible to test all scientific statements and accept that further testing may entail their rejection. There are no statements (such as universal laws) impervious to testing (Popper, 1934). Popper claimed that psychoanalysis, astrology, and Marxism were crucial examples of non-sciences, as no amount of evidence could lead their proponents to disconfirm them. He also claimed that critical rationalism helped scientists distinguish good theories from weak ones. Fertility was one criterion also used by Popper's and Kuhn's contemporaries to assess the value of scientific theories I. Lakatos and L. Laudan tried in different ways to include it in their conceptions of scientific progress.

Logical positivism and Popper's falsification criterion prevailed in American philosophy of science until Kuhn's Structure of Scientific Revolutions (1962) was published. Although Kuhn did not argue that science was relativized by cultural worldviews, this is how many philosophers of science interpreted his historical model of scientific change. Their criticism was on grounds of Kuhn's relativistic assumptions 
about scientific development, i.e., that after a revolution science did not progress but simply shifted world views, together with the under-determination of theories by experimentation. Also, more than a few sociologists of scientific knowledge claimed that it was Kuhn's incommensurability thesis that inspired the field of science studies, of which social constructivism is the most radical version. The exponential growth of this discipline after the mid 1970s, which also got its impetus from structuralist history, literary criticism, and scientific-technological pessimism, contributed to intellectual debates on the sociological nature of science, the critique of science as Western imperialism at work, the fight for equality with science by alternative worldviews, and a post-modern revolution in science education.

It has been quite difficult to transcend the relativistic image of science created by the so-called intellectual descendants of Kuhn and standpoint epistemologies that sprung from traditional courses in science and technology studies. Unfortunately, the philosophical work of M. Polanyi (1958) on the non-subjectivist unspecifiability of personal knowledge in both intellectual work and practical skills is still not well known in the United States. On the other hand, the attempt by H. Putnam (1997) to find a middle ground between metaphysical realism and relativism/subjectivism remained unconvincing, and did not succeed in dethroning from science studies the views of ociologists of science such as feminist S. Harding, social epistemologists like S. Fuller, and critics of Popper such as radical philosopher P. Feyerabend. These and other causes contributed to the erosion of the traditional conception of science as a privileged, objective, neutral epistemological field and, therefore, to the blurring of the demarcation between science and other types of knowledge.

We need to look a criterion of demarcation that is more convincing to students than the inflammatory discourse of the epistemological relativists and other ideologists of science. Scientific illiteracy is leads even those who took high school and college courses in science to accept uncritically weird things such as astrology, the paranormal, extra-sensory perception, unidentified flying object abductions, near-death experiences, channeling, Holocaust denial, homeopathy and other alternative therapies, palmistry, divination, scientific remote viewing, etc. The public does not see how science is radically different from ideology either.

\section{INFORMING SCIENCE (IS) METHODOLOGIES}

\section{Exercises in the Demarcation Criterion:}

a. Which of the following are sciences; b. Which are non-sciences? c. which are in the borderlands between science and nonscience? d. Make list for each category (all that fall into science; all that fall into nonscience; etc.) and justify categorization. Examples: Anthropology; astrology; astronomy; biology; punctuated equilibrium; scientific remote viewing; big bang cosmology; chemistry; creationism; divination; dowsing; geography; geology; history; heliocentrism; Freudian psychoanalysis; evolutionary psychology; homeopathy; iridology; magic; numerology; palmistry; plate tectonics; phrenology; grand theories of economics; physics; psychology; UFOs; sociology; evolution; chiropractic; neurophysiology of brain function; acupuncture; quantum mechanics; chaos and complexity theory; theories of consciousness; hypnosis; superstring theory.(Wynn and Wiggins, 2001, p.1; and Shermer 2001, p. 23-24)

\section{Case Studies}

1. Bad Science versus Good Science (Cold fusion; Misconduct in science); 2. Alternative Therapies; 3. Evolution Debates (evolution vs. creation); 4. Science vs. Politics; 5. Scientific Uncertainty; 6. Science in the Courts. 


\section{Demarcation Criterion between Science and Pseudoscience}

What is a Science? (Outline from M. Bunge,1991a, p.277-278)

Intelligibility: "Is the view clear or obscure? If obscure, can it be elucidated and eventually formalized, or is it inherently obscure and therefore not susceptible to refinement?"; Logical consistency: "Is the view internally consistent or does it contain contradictions? If it does contain inconsistencies, can these be removed by dropping or altering some of the assumptions?"; Systemicity: "Is the view a system or part of one, or is it a stray conjecture that cannot enjoy the support of any other bit of knowledge? If stray, can it be developed into a theory or embedded in one?"; Literalness: "Does the view make any literal sense or is it just an analogy or metaphor? If an analogy, is it shallow or deep, barren or fertile? And is the metaphor indispensable or can it be replaced with a literal statement?"; Testability: "Can the view be checked conceptually or empirically, or is it impregnable to criticism and experience?"; Empirical support: "If the view has been tested, have the results been favorable, unfavorable, or inconclusive?"; External consistency: "Is the view compatible with the bulk of knowledge in all fields of scientific research?"; Originality:" Is the view novel? And does it solve outstanding problems?";

Heuristic power: "Is the view barren or does it raise new and interesting research problems?" Philosophical soundness: "Is the view compatible with the philosophy underlying scientific research? That is, is it epistemologically realistic or does it involve apriorism? And is the view naturalistic or does it posit ghostly entities such as immaterial things or processes, which by hypothesis are inaccessible to experimental control?"

\section{Problems in Pseudoscientific Thinking (Outline of Park, 2000, 48-55)}

\section{Anecdotes do not make science; 2. Scientific language does not make science; 3}

Bold statements do not make claims true; 4. Heresy does not equal correctness; 5. Burden of proof; 6. Rumors do not equal reality; 7. Unexplained is not inexplicable; 8. After-the fact reasoning; 9. Correlation does not mean causation; 10.Coincidence

\section{Boundary Detection Kit (Shermer, 2001, 17-22)}

(questions to ask in determining the (scientific)validity of a claim)

1. How reliable is the source of the claims?; 2. Does this source often make similar claims?; 3 . Have the claims been verified by another source? 4. How does this fit with what we know about the world and how it works? 5. Has anyone, including and especially the claimant, gone out of the way to disprove the claim, or has only confirmatory evidence been sought?; 6 . In the absence of clearly defined proof, does the preponderance of evidence converge to the claimant's conclusion, or a different one?; 7.

Is the claimant employing the accepted rules of reason and tools of research, or have these been abandoned in favor of others that lead to the desired conclusion?; 8. Has the claimant provided a different explanation for the observed phenomena, or is it strictly a process of denying the existent explanation?; 9 . If the claimant has proffered a new explanation, does it account for as many phenomena as the old explanation?; 10.Do the claimant's personal beliefs and biases drive the conclusion, or vice-versa?

\section{Causes of Misconduct in Science (Outline of Gross and Levitt, 1996, 33)}

Scientists were under pressure; Scientists knew, or thought they knew, what the answer would turn out to be if they went to all the trouble of doing the work properly; Scientists were working in a field where individual experiments are not expected to be precisely reproducible 


\section{Nature of Science}

\section{Great Science Writing}

In this category, students analyze texts written by scientists from very different historical periods about their practice, their philosophies of science, and the tension between their scientific positions and those of their peers. The purpose of this exercise is to make students aware of the self-correcting mechanisms of science, the openness of the scientific community to change, and the standards of accuracy demanded by the scientific process. They will also be exposed to the ambiguities of the scientific method, how theories are rejected, how theories are legitimized. Another purpose is to make students aware that it is precisely the fact of scientific change through history that validates it as real science. Bibliography for this part of the course is included in last year's paper.

\section{Conclusion}

We hope to have shown what are some of the social causes of students' inability to demarcate science from pseudoscience, even when they are knowledgeable of scientific principles. Our role as science studies professors is to change people's minds by providing them with informing methodologies that help them find tools to succeed at making this demarcation clear. Only then can we say that we have a scientifically literate population, capable of making serious science policy decisions.

\section{References}

American Association for the Advancement of Science. Project 2061 - Update 2001-2002. Washington: Project 2061.

Atwater, Mary M. (1996). "Social constructivism: infusion into multicultural science education research agenda", Journal of Research in Science Teaching, Vol. 33, No 8, 821-837.

Bolles, Edmund B. (1999). Galileo's Commandment: 2,500 Years of Great Science Writing. New York: W.H. Freeman.

Brockman, J. (ed.)(1995). The Third Culture: Beyond the Scientific Revolution. New York: Simon \& Schuster.

Bunge, Mario (1989). "The Popular perception of science", Transactions of the Ryal Society of Canada, series V, Vol. IV, 269280.

Bunge, Mario (1991). "What is science? Does it matter to distinguish it from pseudoscience?" New Ideas in Psychology, Vol. 9, No. 2, 245-283.

Capra, Fritjof (2000 [1975]). The Tao of Physics: An Exploration of the Parallels between Modern Physics and Eastern Mysticism. Boston: Shambala.

Carson, Rachel (1994 [1962]). Silent Spring. Boston: Houghton Mifflin Company.

Castelão, T. \& Lawless, W. (2001). Informing science (IS) and science and technology studies (STS); the university as decision center (DC) for teaching interdiciplinary research, Informing Science (Special Series: Expanding the Focus), Vol.4, No.3, 87-93.

Chaisson, Eric J. (1990). The Hubble Wars: Astrophysics Meets Astropolitics in the Two-Billion Dollar Struggle Over the Hubble Space Telescope. New York: Harper Perennial.

Chung, Douglas K. Qigong Therapies: A Self-Care Approach-Managing Energy to Promote Holistic Healing and Potential. Grand Rapids, The Chung Institute, 2000.

Comte, Auguste (1988 [1855]). Introduction to Positive Philosophy. Indianapolis: Hackett Publishing Company.

Dewey, John (1984). The Quest for Certainty, in Later Works, Vol. 4. Carbondale: Southern Illinois University Press.

Eisenhart, Margaret \& Finkel, Elizabeth (1998). Women's Science: Learning and Succeeding from the Margins. Chicago: The University of Chicago Press.

Feyerabend, Paul (1987). Farewell to Reason. New York: Verso. 
Fuller, S. (1993). Philosophy, Rhetoric, and the End of Knowledge: The Coming of Science and Technology Studies. Madison, Wisconsin: The University of Wisconsin Press.

Goldfarb, Theodore D. (ed.)(1999). Taking Sides: Clashing Views on Controversial Environmental Issues. Connecticut: McGraw Hill.

Gross, P.R. \& Levitt, N. (eds.)(1994). Higher Superstition: The Academic Left and Its Quarrels with Science. Baltimore: The Johns Hopkins University Press.

Gross, P.r., Levitt, N.R. and Lewis, M. (eds)(1996). The Flight from Science and Reason. New York: The Johns Hopkins University Press.

Hacking, I. (1981). Scientific Revolutions. Oxford: Oxford University Press.

Hacking, I. (1999). The Social Construction of What?. Cambridge: Harvard University Press.

Hanson, N.R. (1958). Patterns of Discovery. London: Cambridge University Press.

Haraway, Donna J. (1991). Simians, Cyborgs, and Women: The Reinvention of Nature. New York: Routledge.

Harding, Sandra (1992). “After the neutrality ideal: science, politics, and strong objectivity”, Social Research, Vol. 59, No. 3, 567-587.

Held, Barbara (1995). “The Real meaning of constructivism”, Journal of Constructivist Psychology, No.8, 305-315.

Judson, Horace F. (1979). The Eighth Day of Creation: The Makers of the Revolution in Biology. New York: Simon and Schuster.

Kennedy, Donald (2001). “College Science: Pass, No Credit”, Science, vol. 293, 31 August, 1557.

Kitcher, Philip (1993). The Advancement of Science: Science Without Legend, Objectivity Without Illusions. New York: Oxford University Press.

Kitcher, Philip (2001). Science, Truth, and Democracy. New York: Oxford University Press Kuhn, Thomas (1970 [1962]). The Structure of Scientific Revolutions. Chicago: The University of Chicago Press.

Lakatos, Imre (1986 [1978]). The Methodology of Scientific Research Programmes. Cambridge: Cambridge University Press.

Laudan, Larry (1978). Progress and Its Problems: Towards a Theory of Scientific Growth. Berkeley: University of California Press.

Lawless, W. \& Castelão, T. (2001). "The university between technology and society: bridge or decision center?”, Technology and Society, Vol.20, No.2, Summer, 6-17.

Levitt, N. (1999). Prometheus Bedeviled: Science and the Contradictions of Contemporary Culture. New Brunswick: Rutgers University Press.

Masters, R. (1993). Beyond Relativism: Science and Human Values. Hanover: University Press of New England.

McInerney, Joseph. (1991) "Public education”, Biotechnology Education, vol.2, No. 3, 98-100.

Merchant, Carolyn (1980). The Death of Nature: Women, Ecology, and the Scientific Revolution. New York: Harper \& Row.

Nanda, Meera (1991). "Is Modern science a Western patriarchical myth? A critique of the populist orthodoxy", South Asia Bulletin, Vol. XI, No. 1 \& 2, 32-61.

Park, Robert (2000). Voodoo Science: The Road From Foolishness to Science. New York: Oxford University Press.

Polanyi, Michael (1962 [1958]). Personal Knowledge: Towards a Post-Critical Philosophy. Chicago: The University of Chicago Press.

Putnam, H. (1981). Reason, Truth, and History. New York: Cambridge University Press.

Ruse, Michael (2000). The Evolution Wars - a Guide to the Debates. New Brunswick: Rutgers University Press.

Shamos, Morris H. (1995). The Myth of Scientific Literacy. New Brunswick: Rutgers University Press.

Shapin, S. "Guests in the President's House", London Review of Books, 18 october 2001, 3-7.

(1997). Why People Believe Weird Things: Pseudoscience, Superstition, and Other Confusions of Our Time. New York: W.H. Freeman and Company.

Shermer, Michael (2001). The Borderlands of Science: Where Sense Meets Nonsense. Oxford: Oxford University Press. 


\section{Epistemology of Science}

Sirico, Robert (2001). "Faith and Freedom", The Wall Street Journal, December 24, p. A10.

Stokstad, Erik (2001). "Reintroducing the Intro Course", Science, vol. 293, 31 August, 1608-1610.

Stove, David (2001). Scientific Irrationalism: Origins of a Postmodern Cult. New Brunswick: Transaction Publishers.

Sukys, Paul (1999). Lifting the Scientific Veil: Science Appreciation for Non-scientists. New York: Rowman \& Littlefield Publishers, Inc.

Taubes, G. (1993). Bad Science: The Short Life and Weird Times of Cold Fusion. New York: Random House.

Wilson, E.O. Sociobiology (1980). Cambridge: Harvard University Press.

Wilson, E.O. (1995). "Science and ideology", Academic Questions, vol.8, No.3, 73-81.

Wynn, Charles M. \& Wiggins, Arthur W. (2001). Quantum Leaps in the Wrong Direction: Where Real Science Ends and Pseudoscience Begins. Washington DC: Joseph Henry Press. 